\title{
Manganese-Based Catalysts for Indoor Volatile Organic Compounds Degradation with Low Energy Consumption and High Efficiency
}

\author{
Yanbo $\mathrm{Li}^{1}$ · Shuhe Han ${ }^{1}$ Liping Zhang ${ }^{2} \cdot$ Yifu Yu ${ }^{1}$
}

Received: 20 October 2021 / Revised: 1 November 2021 / Accepted: 6 November 2021 / Published online: 13 December 2021

(C) The Author(s) 2021

\begin{abstract}
With the development of industrialization, the emission of volatile organic compounds (VOCs) to atmosphere causes serious environmental problems and the treatment of VOCs needs to consume a lot of energy. Moreover, indoor VOCs are seriously harmful to human health. Thus, there is an urgent requirement for the development of indoor VOCs treatment technologies. Catalytic degradation of VOCs, as a low energy consumption, high efficiency, and easy to achieve manner, has been widely studied in related fields. As a kind of transition metal catalyst, manganese-based catalysts have attracted a lot of attention in the catalytic degradation of VOCs because of their unique advantages including high efficiency, low cost, and excellent stability. This paper reviews the state-of-the-art progress of manganese-based catalysts for VOCs catalytic degradation. We introduce the thermocatalytic, photocatalytic and photo-thermocatalytic degradation of VOCs on manganese-based catalysts in this paper. The optimization of manganese-based catalysts by means of structural design, decorating modification and defect engineering is discussed.
\end{abstract}

\section{Graphical Abstract}

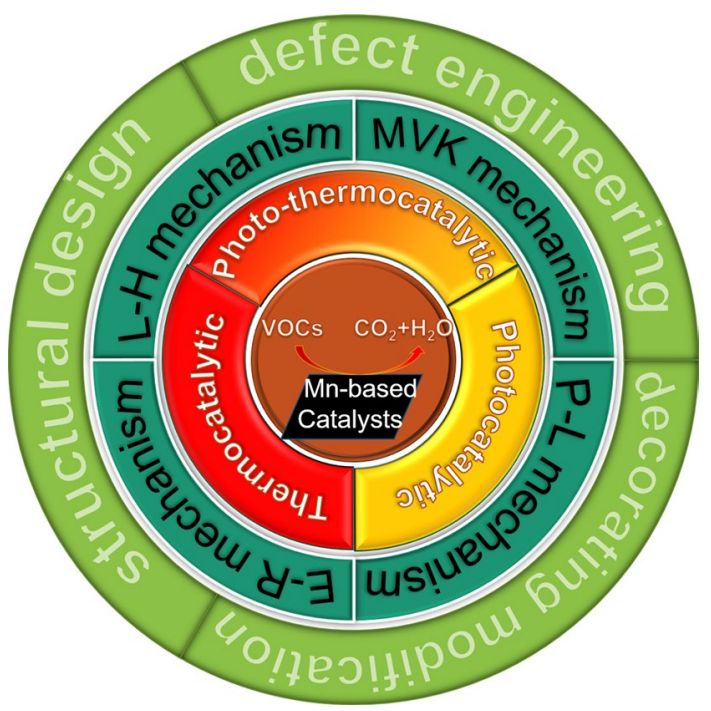

Keywords VOCs degradation · Manganese-based catalysts $\cdot$ Catalysis $\cdot$ Low energy consumption

Liping Zhang

Lzhang030@e.ntu.edu.sg

Yifu Yu

yyu@tju.edu.cn

Extended author information available on the last page of the article

\section{Introduction}

Energy and environmental problems are the two major problems in today's world; in particular, air pollution is becoming more and more serious [1-5]. VOCs are a kind of 
organic compounds with melting point lower than room temperature and boiling point between 50 and $260{ }^{\circ} \mathrm{C}$ [3-11]. VOCs come from a wide range of sources, including coatings, organic chemicals, petrochemical, pharmaceutical and catering industries $[3,5,12-16]$. VOCs are also important components of indoor air pollutants $[16,17]$. Therefore, improving indoor air quality by controlling VOCs pollution is conducive to improving living environment and human health [18-21]. There are three main ways to control indoor VOCs, including source pollution control, ventilation dilution and purification treatment [22-28]. Reducing the source pollution is an effective approach; however, the use of VOCs is necessary and inevitable [29]. Ventilation dilution, i.e., outdoor air replaces indoor air in a given space, is the easiest way to reduce the concentration of VOCs. However, the efficiency of this method is very low. Besides, the benefits of ventilation dilution depend on the relative concentration of pollution between indoor and outdoor air; sometimes, it may introduce new outdoor pollutants [23]. Purification treatment of VOCs is an ideal way to deal with indoor VOCs pollution, which transforms indoor VOCs into bound states or other harmless substances [25-28]. However, purification treatment of VOCs needs to consume a lot of energy. How to achieve the effect of pollutant degradation and reducing energy consumption through effective design is a subject worthy of in-depth research.

Based on whether the treated products contain VOCs, the purification treatment of VOCs can be divided into two types, i.e., recycling treatment and destruction treatment [30]. Recycling treatment of VOCs separates VOCs and clean air by passing the polluted air through a special device. The purification function is realized; however, a secondary treatment is needed to degrade the VOCs [31-34]. In contrast, the destruction treatment directly removes VOCs by decomposing them into non-toxic gases using catalytic/noncatalytic methods [30]. Among them, catalytic oxidation method possesses the advantages of low energy consumption, high efficiency and no secondary pollution [35-37].

Till now, a large number of catalysts including noble metals and transition metal oxides have been developed for catalytic oxidation of VOCs. Among them, manganesebased catalysts have attracted tremendous attention due to their excellent catalytic performance, unique structure, large specific surface area, excellent adsorption ability and low cost [36, 38-41]. Lots of progresses have been made using manganese-based catalysts for the degradation of VOCs [28, 35, 42-44]. This review summarizes the state-of-the-art progress on the design, synthesis and application of manganesebased catalysts for VOCs degradation. A brief introduction of the VOCs degradation mechanisms is first described, followed by the discussions on the thermocatalysis, photocatalysis and photo-thermocatalysis of VOCs degradation.
Finally, we provide some personal insights into the challenges and future research directions in this field.

\section{Mechanisms for VOCs Degradation}

The mechanism for VOCs degradation is complicated due to the large number of different types of VOCs and catalysts. Four mechanisms for VOCs oxidation have been proposed, i.e., Langmuir-Hinshelwood (L-H) mechanism, Eley-Rideal (E-R) mechanism, simple power law (P-L) mechanism and Mars-van Krevelen (MVK) mechanism [45-48]. Among them, MVK mechanism can be used to explain most of the catalytic degradation reactions $[47,49,50]$. In this section, we will introduce different types of mechanisms with particular focusing on the MVK mechanism.

\section{Langmuir-Hinshelwood (L-H) Mechanism}

$\mathrm{L}-\mathrm{H}$ mechanism takes surface reaction as the speed determining step. There are three steps in $\mathrm{L}-\mathrm{H}$ mechanism, including the adsorption of reactants, catalytic reaction and the desorption of products [45]. Most of the surface reactions can be explained by $\mathrm{L}-\mathrm{H}$ mechanism. Based on the $\mathrm{L}-\mathrm{H}$ mechanism, Tarjomannejad et al. [45] carried out a kinetic study of the catalytic oxidation of toluene over $\mathrm{LaMnO}_{3}$ catalyst. The results showed that LH-OS-ND (adsorption of reagents on the same type of sites and non-dissociative adsorption of oxygen) was the most likely mechanism to predict the experimental data. The correlation coefficient was $R^{2}=0.9952$. Hua et al. [51] proposed a new L-H dualsite mechanism to explain the experimental observations of the catalytic ozonation of toluene over $\mathrm{MnO}_{2}$ /graphene via a steady-state kinetic study.

\section{Eley-Rideal (E-R) Mechanism}

Both E-R mechanism and $\mathrm{L}-\mathrm{H}$ mechanism are based on the Langmuir model. The difference is that in $\mathrm{E}-\mathrm{R}$ mechanism, only one of the reactants is adsorbed on the surface of catalyst, which then reacts with the non-adsorbed reactants [52]. Wang et al. [46] synthesized a series of spinel oxides $\mathrm{ZnNi}_{x} \mathrm{Co}_{2-x} \mathrm{O}_{4}(x=0-0.8)$, and they found that the catalytic combustion behavior of methane on Ni-poor $\mathrm{ZnNi}_{x} \mathrm{Co}_{2-x} \mathrm{O}_{4}$ spinels could be fitted by E-R mechanism.

\section{Power Law (P-L) Mechanism}

P-L mechanism is a dynamic distribution fitting method proposed by statistical physicists for scale-free phenomena in nature, which has been widely used in various fields [47]. Maghsoodi et al. [53] determined the apparent activation 
energy of the catalytic ozonation of toluene over $\mathrm{MnO}_{2}$ /graphene using P-L mechanism.

\section{Mars-van Krevelen (MVK) Mechanism}

There are two steps in the MVK mechanism, i.e., lattice oxygen in the catalyst oxidizes VOCs, and then the catalyst adsorbs and converts gaseous oxygen into lattice oxygen [47-50]. Utsumi et al. [47] found out MVK model can well simulate the catalytic oxidation of acetyl acetate over $\mathrm{La}_{1-x} \mathrm{Ca}_{x} \mathrm{FeO}_{3}$. But, without $\mathrm{H}_{2} \mathrm{O}$ and $\mathrm{CO}_{2}$, simple P-L mechanism can also fit the data. He et al. [49] studied the catalytic oxidation behavior and kinetics of benzene, toluene and ethyl acetate on Pd/ZSM-5 and found MVK model can express the reaction rate of all VOCs, while P-L model is only applicable to benzene. Du et al. [50] pointed out the catalytic oxidation of toluene on low-Pt bimetal compounds $\left(\mathrm{PtNi}_{3}-\mathrm{C}\right.$ and $\left.\mathrm{PtFe}_{3}-\mathrm{C}\right)$ catalyst following the MVK mechanism, in which the active oxygen helps to remove toluene adsorbed on the catalyst (Fig. 1).

It should be noticed that not all catalytic reactions follow only one mechanism. Wang et al. [54] studied the oxidation kinetics of benzene on $\mathrm{ACo}_{2} \mathrm{O}_{4}(\mathrm{~A}=\mathrm{Cu}, \mathrm{Ni}$ and $\mathrm{Mn})$ catalysts. The results indicate that the oxidation of benzene can be well fitted with both the MVK mechanism and L-H mechanism. The surface reaction of adsorbed MEK with oxygen was considered as the rate-determining step in the model.

\section{Thermocatalytic Degradation of VOCs on Manganese-Based Catalysts}

Thermocatalysis technology, developing from direct thermal degradation, is the most effective method in VOCs treatment [55]. For indoor air with low concentration of VOCs, the

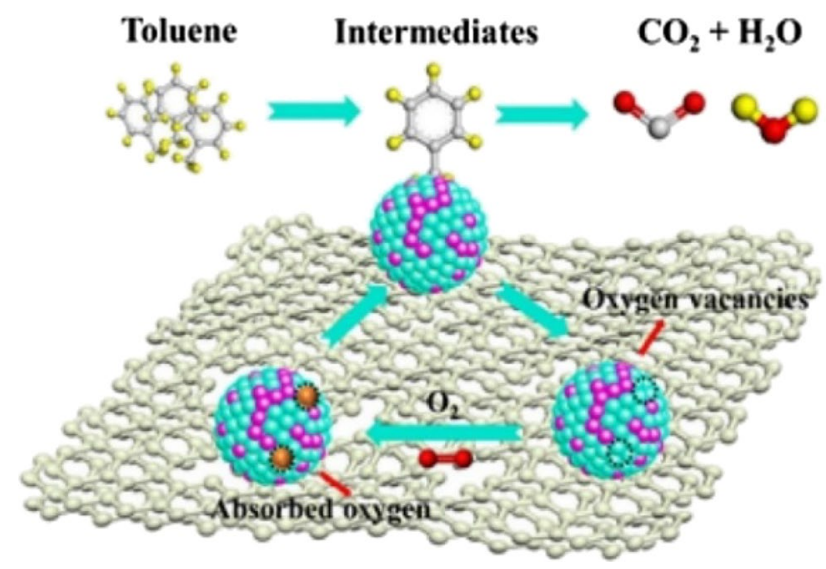

Fig. 1 The catalytic combustion mechanism of toluene. Reprinted with permission from Ref. [50]. Copyright 2020 Elsevier direct thermal degradation is difficult to achieve due to the high energy consumption. Besides, the thermal degradation also generates harmful by-products [56]. In contrast, thermocatalytic degradation is an ideal method for indoor VOCs degradation because of its better efficiency and lower energy consumption. To date, many catalysts including transition metal and noble metal-based catalysts have been used for thermocatalysis [57]. Although noble metal-based catalysts possess the advantages of high efficiency and low ignition temperature, the great cost and poor thermal stability limit their wide application [58]. Transition metal-based catalysts generally have the advantages of excellent stability and low cost; however, they suffer from low catalytic efficiency [36, 38-41, 59]. Mn, a typical earth-abundant transition metal with diverse valence states, is widely used in catalytic reaction [60]. Mn-based catalysts have been widely studied in thermocatalytic degradation of VOCs; however, the catalytic activities still need to be improved [42, 61]. In view of the existing problems, researchers have improved the activity and stability of Mn-based catalyst by means of structural design and decorating modification [36, 38, 39, 42, 61-64].

\section{Structural Design of Manganese-Based Catalysts}

A lot of efforts have been put into the structural design of manganese-based catalysts in order to improve their efficiency toward the thermocatalytic degradation of VOCs. Yang et al. [38] reported the preparation of $\alpha-, \beta-, \gamma$ - and $\delta-\mathrm{MnO}_{2}$ catalysts and evaluated their catalytic performance for toluene degradation. The results showed that the order of degradation efficiency was $\delta-\mathrm{MnO}_{2}>\alpha-\mathrm{MnO}_{2}>\gamma-\mathrm{Mn}$ $\mathrm{O}_{2}>\beta-\mathrm{MnO}_{2}$, which was consistent with the order of oxygen adsorption capacity and low-temperature reducibility (Fig. 2a, b). Li et al. [65] also prepared $\mathrm{MnO}_{2}$ with different phase structures and reported their catalytic oxidation activities of toluene (Fig. 2c, d).

Li et al. [66] synthesized hierarchical hollow $\mathrm{MnO}_{2}$ microspheres, exhibiting efficient catalytic activity toward benzene oxidation. Liu et al. [42] prepared palygorskite-supported Mn oxides, which catalyzed the oxidation of formaldehyde in a complete and efficient way. De Luna et al. [67] prepared octahedral molecular sieve type manganese oxide (K-OMS 2) catalysts with outstanding low-temperature activity, which achieved $100 \%$ toluene conversion efficiency and $98 \%$ benzene conversion efficiency at $523 \mathrm{~K}$ and $565 \mathrm{~K}$, respectively. Nguyen Dinh et al. [68] reported the synthesis of $\mathrm{MnCO}_{3}$-carbon composites and 3D porous $\varepsilon-\mathrm{MnO}_{2}$ microcubes (PEMD) with great porosity, strong reducibility, high lattice oxygen reactivity and large $\mathrm{Mn}^{4+}$ fraction, significantly improving the catalytic performances of toluene complete oxidation. Piumetti et al. [36] prepared three mesoporous manganese oxide catalysts $\left(\mathrm{Mn}_{3} \mathrm{O}_{4}, \mathrm{Mn}_{2} \mathrm{O}_{3}\right.$ and $\mathrm{Mn}_{x} \mathrm{O}_{y}$ ) and evaluated their activities for total oxidation of 

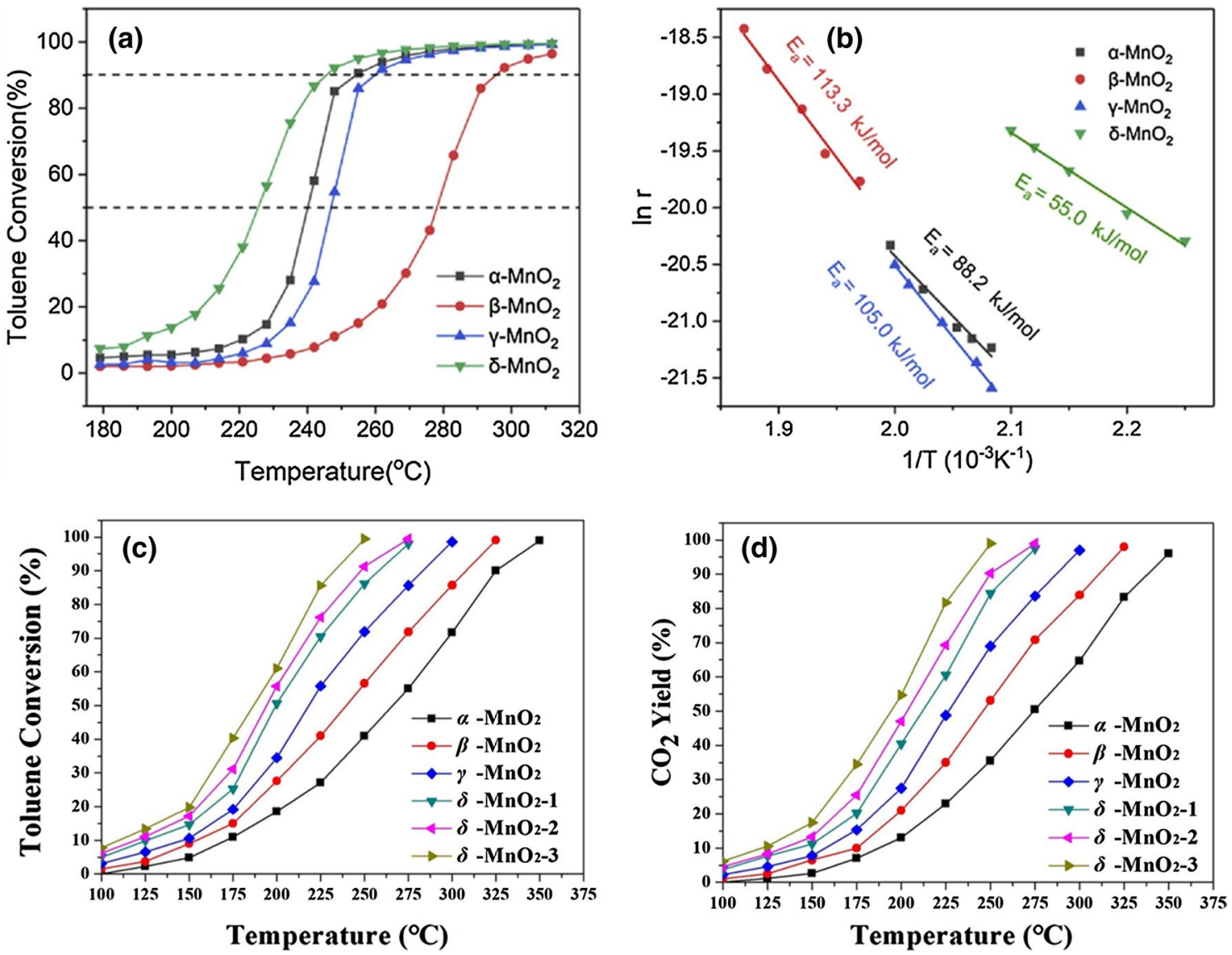

Fig. 2 Profile of a toluene conversion, b Arrhenius fitting curves as functions of reaction temperature over $\alpha-, \beta-, \gamma$ - and $\delta-\mathrm{MnO}_{2}$. Reprinted with permission from Ref. [38]. Copyright 2019 Elsevier. c Toluene catalytic oxidation performances and $\mathbf{d} \mathrm{CO}_{2}$ yields dur-

VOCs (ethylene, propylene, toluene and their mixture). The results demonstrated that among various manganese oxides, $\mathrm{Mn}_{3} \mathrm{O}_{4}$ had the best catalytic performance for all the VOCs (Fig. 3) [36].

\section{Decorating Modification of Manganese-Based Catalysts}

Decorating modification is another effective method to improve thermocatalytic activity. Ali et al. [59] prepared a series of triple-oxide $\left(\mathrm{CeO}_{2}, \mathrm{ZrO}_{2}\right.$ and $\left.\mathrm{TiO}_{2}\right)$ as support and then used (i) Mn impregnation or/and (ii) Au deposition-precipitation to obtain the corresponding catalyst (Mn-only catalysts, $\mathrm{Au}$-only catalysts and $\mathrm{Au}-\mathrm{Mn}$-containing catalysts). In their report, propane was used to evaluate the catalytic performance. The results showed that a strong metal-metal interactions between $\mathrm{Au}$ and $\mathrm{Mn}$ significantly increased the catalytic activity of the $\mathrm{Au}-\mathrm{Mn} / \mathrm{TOS}$ catalyst compared with the sole metal Au/TOS and Mn/TOS catalysts (Fig. 4a) [59]. Zhang et al. [69] decorated different amounts of single-atom

ing toluene oxidation obtained with different phase structured $\mathrm{MnO}_{2}$ catalysts. Reprinted with permission from Ref. [65]. Copyright 2019 Elsevier

Pt into $\mathrm{MnO}_{2}$, among which, the activity of $0.1 \% \mathrm{Pt} / \mathrm{MnO}_{2}$ sample showed the best performance. The conversion rate of toluene reached $100 \%$ at $80{ }^{\circ} \mathrm{C}$, and more than $80 \%$ of toluene conversion was achieved at the gas hourly space velocity $(\mathrm{GHSV})$ of $60 \mathrm{~L} / \mathrm{gh}$ at room temperature $\left(28^{\circ} \mathrm{C}\right)$ (Fig. 4b) [69].

Perovskite-type catalysts $\left(\mathrm{ABO}_{3}\right)$ have the characteristics of great thermal stability, unusual valence states of the transition metal ions in their structures, tunable redox properties and excellent low-temperature activity. Moreover, cations at $\mathrm{A}$ and $\mathrm{B}$ sites can be decorated by other ions, which produces more defects sites and oxygen vacancies [25]. Li and his collaborators [70] studied the catalytic oxidation of hexane by $\mathrm{La}_{0.8} \mathrm{Ce}_{02} \mathrm{MnO}_{3} /$ mesoporous ZSM-5. The results showed that $\mathrm{Ni}$ doping at $\mathrm{Mn}$ sites in $\mathrm{La}_{0.8} \mathrm{Ce}_{0.2} \mathrm{MnO}_{3}$ could promote the low-temperature catalytic activity due to the enhancing electronic transfer among the $\mathrm{La}, \mathrm{Ce}, \mathrm{Ni}, \mathrm{Mn}$ and mesoporous ZSM-5, as well as the promoting migration and distribution of the surface oxygen species. Maghsoodi et al. [53] proved that excess manganese in $\mathrm{LaMn}_{1+x} \mathrm{O}_{3+\delta}$ 

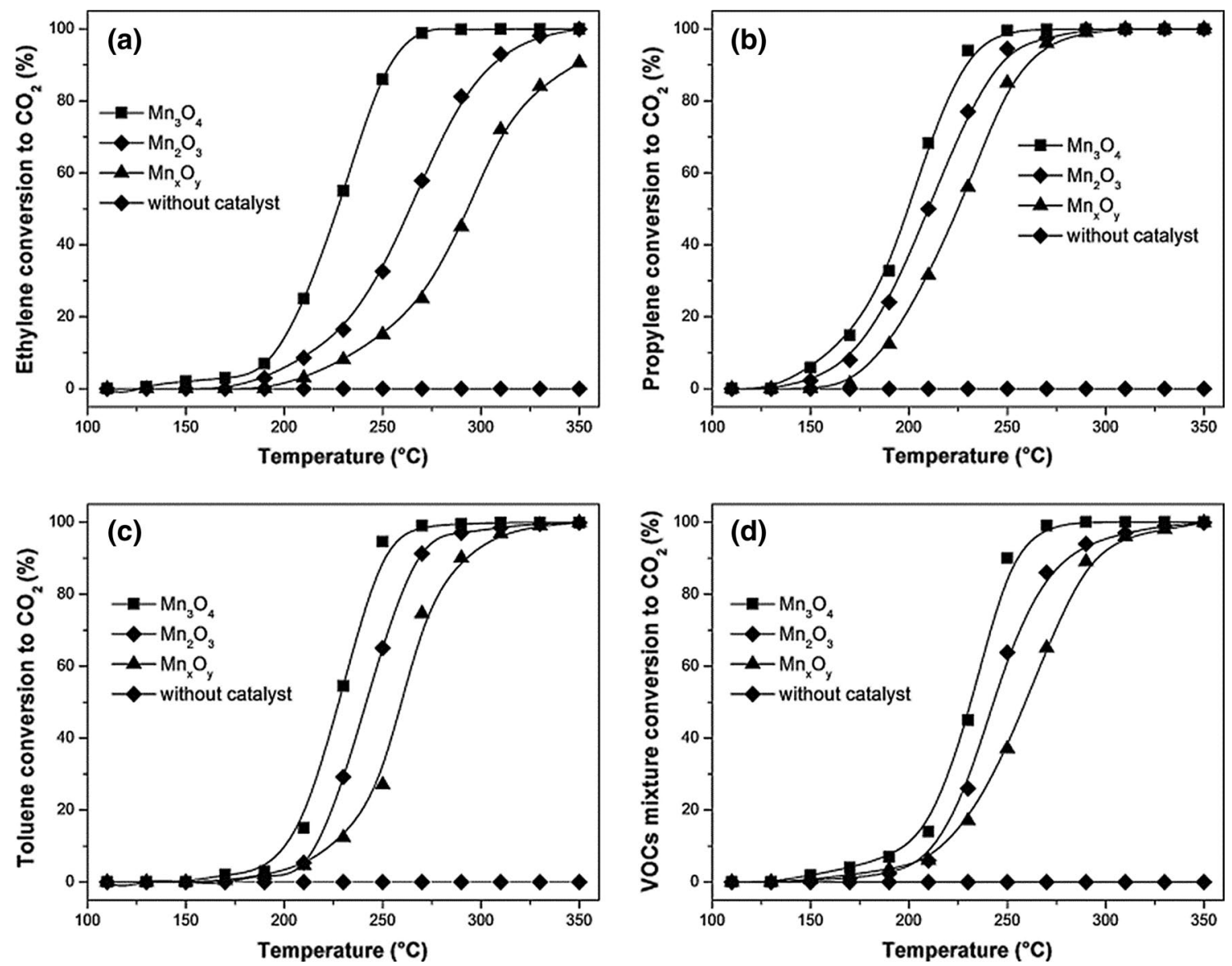

Fig. 3 Catalytic results of powder catalysts for the total oxidation of a ethylene, b propylene, $\mathbf{c}$ toluene and $\mathbf{d}$ VOC mixture (ethylene, propylene and toluene) as a function of the reaction temperature. Reprinted with permission from Ref. [36]. Copyright 2014 Elsevier

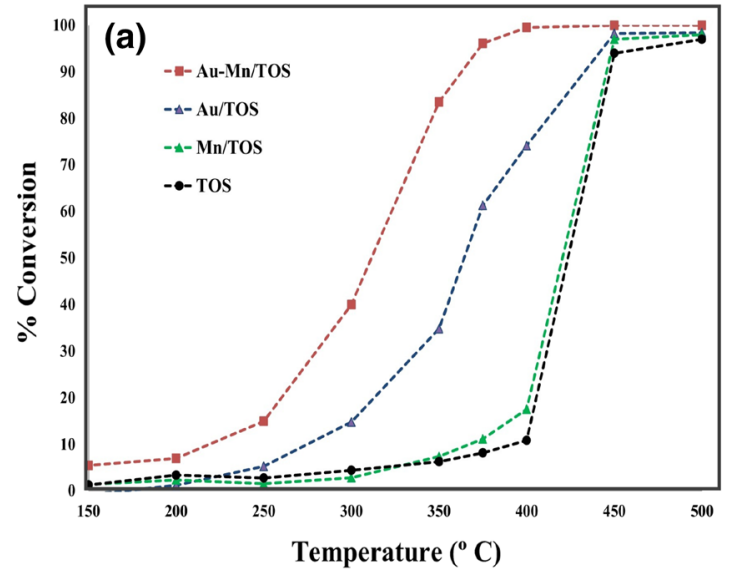

Fig. 4 a Comparison of the catalytic activity for the propane total oxidation by $\mathrm{Au} / \mathrm{TOS}, \mathrm{Mn} / \mathrm{TOS}$ and $\mathrm{Au}-\mathrm{Mn} / \mathrm{TOS}$ and TOS catalysts. Reprinted with permission from Ref. [59]. Copyright 2014 Elsevier.

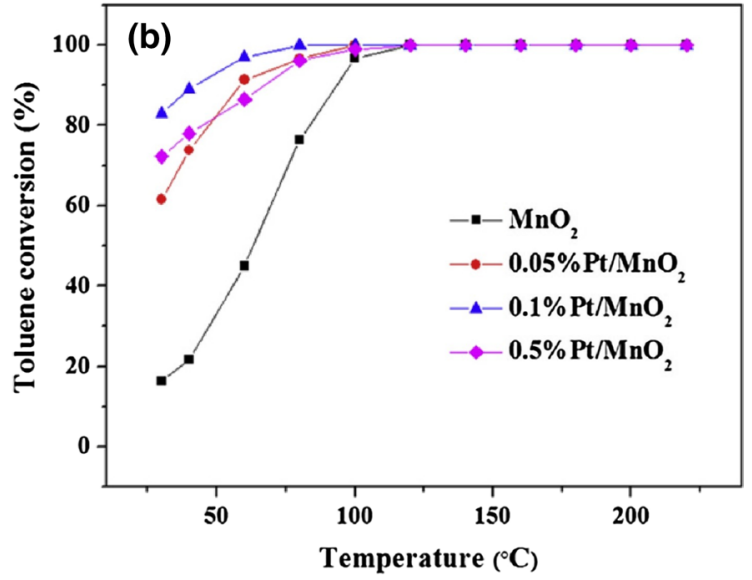

b Temperature-dependent toluene conversion by $\mathrm{MnO}_{2}$ and Pt-deposited $\mathrm{MnO}_{2}$ catalysts. Reprinted with permission from Ref. [69]. Copyright 2019 Elsevier 
perovskite also had a promoting effect on the oxidation of trichloroethylene (TCE) in air. Tarjomannejad et al. [45] showed that $\mathrm{Fe}$-containing perovskite catalyst had a better activity than $\mathrm{Cu}$-containing perovskite catalyst. Liu et al. [40] synthesized $\mathrm{SmMnO}_{3}$ (SMO) perovskite and deposited $\gamma-\mathrm{MnO}_{2}$ on the surface of SMO. The results showed that the temperature at which the conversion reached 50\% and $90 \%\left(T_{50 \%}\right.$ and $\left.T_{90 \%}\right)$ of toluene by $\gamma-\mathrm{MnO}_{2} / \mathrm{SMO}$ are $187^{\circ} \mathrm{C}$ and $208^{\circ} \mathrm{C}$, respectively. The mineralization degree of toluene was $192{ }^{\circ} \mathrm{C}$ and $210^{\circ} \mathrm{C}$, which was lower than that of $\gamma-\mathrm{MnO}_{2}\left(219^{\circ} \mathrm{C}\right.$ and $251^{\circ} \mathrm{C} ; 223^{\circ} \mathrm{C}$ and $\left.253^{\circ} \mathrm{C}\right)$ and SMO $\left(232{ }^{\circ} \mathrm{C}\right.$ and $260{ }^{\circ} \mathrm{C} ; 236^{\circ} \mathrm{C}$ and $\left.263{ }^{\circ} \mathrm{C}\right)$. In addition, the catalytic oxidation ability of $\gamma-\mathrm{MnO}_{2} / \mathrm{SMO}$ toward various aromatic VOCs including ethylbenzene, o-xylene and benzene was also studied. The order of VOCs conversion and $\mathrm{CO}_{2}$ yield for $T_{50 \%}$ was as follows: toluene $\left(187^{\circ} \mathrm{C}\right.$ and $\left.192{ }^{\circ} \mathrm{C}\right)<$ ethylbenzene $\left(201{ }^{\circ} \mathrm{C}\right.$ and $\left.206^{\circ} \mathrm{C}\right)<$ benzene $\left(213{ }^{\circ} \mathrm{C}\right.$ and $\left.223{ }^{\circ} \mathrm{C}\right)<$ o-xylene $\left(232{ }^{\circ} \mathrm{C}\right.$ and $\left.236^{\circ} \mathrm{C}\right)$ (Fig. 5) [40].

In summary, the thermocatalytic degradation of VOCs on different manganese-based catalysts is listed in Table 1.

\section{Photocatalytic Degradation of VOCs on Manganese-Based Catalysts}

Since Fujishima and Honda [71] first reported the photolysis of water over $\mathrm{TiO}_{2}$, lots of efforts have been devoted to developing photocatalysts for various photocatalytic reactions. In fact, the research on photocatalytic degradation
Fig. 5 VOCs oxidation: a toluene conversion and $\mathbf{b} \mathrm{CO}_{2}$ yield for toluene oxidation versus reaction temperature over $\gamma-\mathrm{MnO}_{2} / \mathrm{SMO}$, SMO and $\gamma-\mathrm{MnO}_{2}$; c Benzene, ethylbenzene and o-xylene conversion and $\mathbf{d ~} \mathrm{CO}_{2}$ yield for BEX oxidation versus reaction temperature over $\gamma$ - $\mathrm{MnO}_{2} / \mathrm{SMO}$. Reprinted with permission from Ref. [40]. Copyright 2019 Elsevier
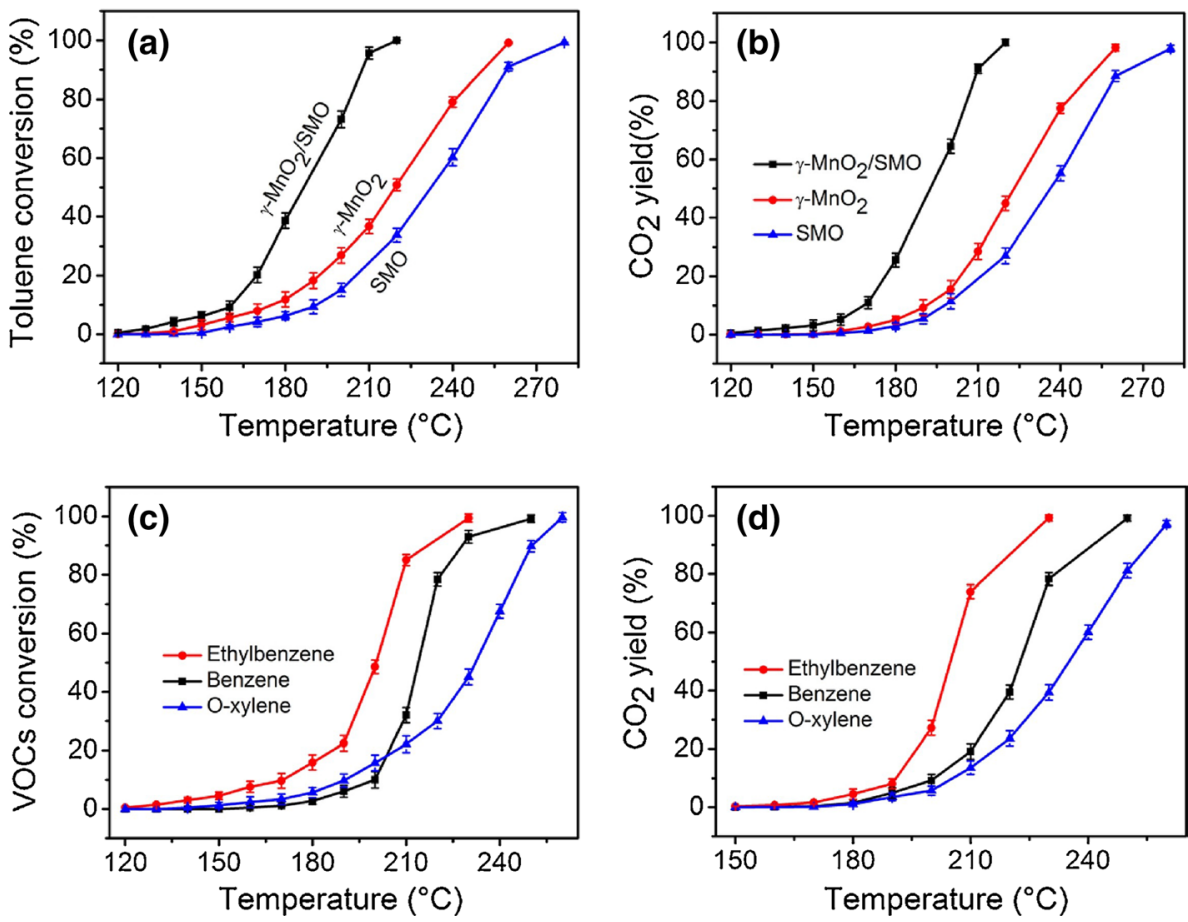

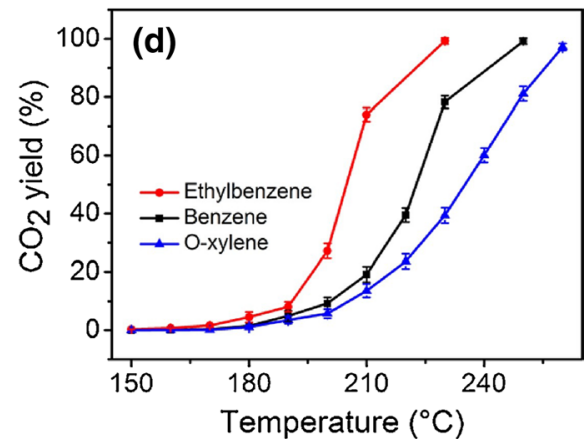

Table 1 Comparison of thermocatalytic degradation of VOCs on different manganese-based catalysts

\begin{tabular}{|c|c|c|c|c|}
\hline Catalyst & Synthesis method & Species & Result & Refs \\
\hline Hierarchical hollow $\mathrm{MnO}_{2}$ microspheres & Hydrothermal method & Benzene & $T_{50 \%}=493 \mathrm{~K}, T_{90 \%}=525 \mathrm{~K}$ & {$[66]$} \\
\hline Palygorskite-supported Mn oxides & Sedimentation & Formaldehyde & $T_{90 \%}=494 \mathrm{~K}$ & [42] \\
\hline K-OMS 2 & Hydrothermal method & $\begin{array}{l}\text { Toluene } \\
\text { Benzene }\end{array}$ & $\begin{array}{l}\text { Toluene } T_{100 \%}=523 \mathrm{~K} \\
\text { Benzene } T_{98 \%}=565 \mathrm{~K}\end{array}$ & {$[67]$} \\
\hline PEMD & Hydrothermal method & Toluene & $T_{90 \%}=516 \mathrm{~K}$ & {$[68]$} \\
\hline $\mathrm{Au}-\mathrm{Mn} / \mathrm{TOS}$ & Impregnation method & Propane & $T_{95 \%}=648 \mathrm{~K}, T_{100 \%}=673 \mathrm{~K}$ & {$[59]$} \\
\hline $0.1 \% \mathrm{Pt} / \mathrm{MnO}_{2}$ & Hydrothermal method & Toluene & $T_{80 \%}=301 \mathrm{~K}, T_{100 \%}=353 \mathrm{~K}$ & [69] \\
\hline $\mathrm{La}_{0.8} \mathrm{Ce}_{0.2} \mathrm{Mn}_{0.5} \mathrm{Ni}_{0.5} \mathrm{O}_{3} / \mathrm{MZ}$ & Impregnation method & Hexane & $T_{50 \%}=579 \mathrm{~K}, T_{90 \%}=613 \mathrm{~K}$ & [70] \\
\hline $\mathrm{LaMn}_{1.2} \mathrm{O}_{3}$ & Gel combustion & Trichloroethylene & $T_{50 \%}=613 \mathrm{~K}, T_{90 \%}=678 \mathrm{~K}$ & {$[53]$} \\
\hline $\mathrm{La}_{0.8} \mathrm{Ce}_{0.2} \mathrm{Mn}_{0.3} \mathrm{Fe}_{0.7} \mathrm{O}_{3}$ & Sol-gel method & Toluene & $T_{50 \%}=452 \mathrm{~K}, T_{100 \%}=475 \mathrm{~K}$ & [45] \\
\hline
\end{tabular}


of VOCs also began with using $\mathrm{TiO}_{2}$ as catalyst, and then extended to other catalysts, including manganese-based catalysts $[43,72,73]$. Frank and Bard $[74,75]$ studied the reduction of $\mathrm{CN}^{-}$in water, which was the first application of $\mathrm{TiO}_{2}$ in environmental purification. Kraeutler and Bard [76] proposed the first organic photocatalysis reaction $\left(\mathrm{CH}_{3} \mathrm{COOH} \rightarrow \mathrm{CH}_{4}+\mathrm{CO}_{2}\right)$. Pruden and Ollis [72] carried out a semiconductor sensitized reaction for the oxidative mineralization of organic pollutants (the degradation of trichloroethylene in water), which introduced photocatalysis into the field of VOCs catalytic degradation for the first time. However, $\mathrm{TiO}_{2}$ has a wide band gap energy $(3.2 \mathrm{eV}$ for anatase) and can only utilize the ultraviolet light (about $3 \%-5 \%$ of the solar energy), which greatly limits its practical application $[77,78]$. Therefore, it has become an important research topic to develop UV-Vis photocatalyst with narrow band gap. $\mathrm{MnO}_{2}$ has become an attractive candidate for photocatalytic reaction in wastewater and waste gas treatment due to its low cost, small band gap and non-toxic characteristics [43, 78-80].

\section{Mechanism of Photocatalytic Degradation of VOCs}

Generally, there are three key steps in a semiconductor photocatalytic reaction. First, photo-induced electrons $\left(\mathrm{e}^{-}\right)$and holes $\left(\mathrm{h}^{+}\right)$are generated when the photocatalyst is excited by photons with energy greater than or equal to the band gap energy of photocatalyst $(E g)$ [81]. Second, the photoexcited carriers separate and migrate to the surface of photocatalyst. Third, $\mathrm{e}^{-}$with strong reducibility reacts with $\mathrm{O}_{2}$ to form $\mathrm{O}_{2}^{-}$, while $\mathrm{h}^{+}$with strong oxidation combines with $\mathrm{H}_{2} \mathrm{O}$ or $\mathrm{OH}^{-}$adsorbing on the photocatalyst surface to form $\cdot \mathrm{OH}$.
These two substances further react with VOCs and convert them into $\mathrm{CO}_{2}$ and $\mathrm{H}_{2} \mathrm{O}$ (Fig. 6) [81].

Although Fig. 6 is the mechanism summarized by scientists based on $\mathrm{TiO}_{2}$, it is still applicable to other semiconductor catalysts, including manganese-based photocatalyst.

\section{Optimization of Manganese-Based Photocatalyst}

As a kind of traditional thermocatalysts, manganese-based catalysts have also been used as photocatalysts in photocatalytic reactions. Chhabra et al. [80] prepared manganese dioxide $\left(\mathrm{MnO}_{2}\right)$ nanorods over reduced graphene oxide (RGO) nanocomposites, which exhibited efficient photocatalytic activity for the removal of a colored dye (neutral red) from water. This demonstrated that manganese-based catalysts could be used in photocatalytic degradation of VOCs. Other researchers also studied the synthesis of series manganese oxides and evaluated their photocatalytic performance [82-84]. The mixed valence state of $\mathrm{Mn}$ and the presence of active oxygen $\left(\cdot \mathrm{OH}\right.$ and $\left.\cdot \mathrm{O}_{2}^{-}\right)$were found to play important roles in promoting the photodegradation of VOCs.

Manganese-based photocatalysts have also been used in the dye removal, which is a combination of adsorption, oxidation and photocatalysis. The catalytic mechanism is similar to the photocatalytic degradation of VOCs. Fang et al. [10] prepared Mg-doped OMS-2 nanorod catalysts using a hydrothermal redox reaction, and the catalytic degradation of benzene increased significantly under full solar spectrum (UV-Vis-IR) irradiation from a Xe lamp. The main reasons for the degradation of outstanding benzene were the substitution of a small amount of $\mathrm{Mg}$ cation for $\mathrm{Mn}^{4+}$ in OMS-2. Chan et al. [85] prepared $\beta-\mathrm{MnO}_{2}$ nanotubes and found the photocatalytic degradation
Fig. 6 Main processes occurring on a semiconductor particle: electron-hole pair generation, charge transfer, electron-hole pair recombination at the surface or in the bulk, and electron and hole-induced chemistry at the surface. Reprinted with permission from Ref. [81]. Copyright 2019 WILEY-VCH

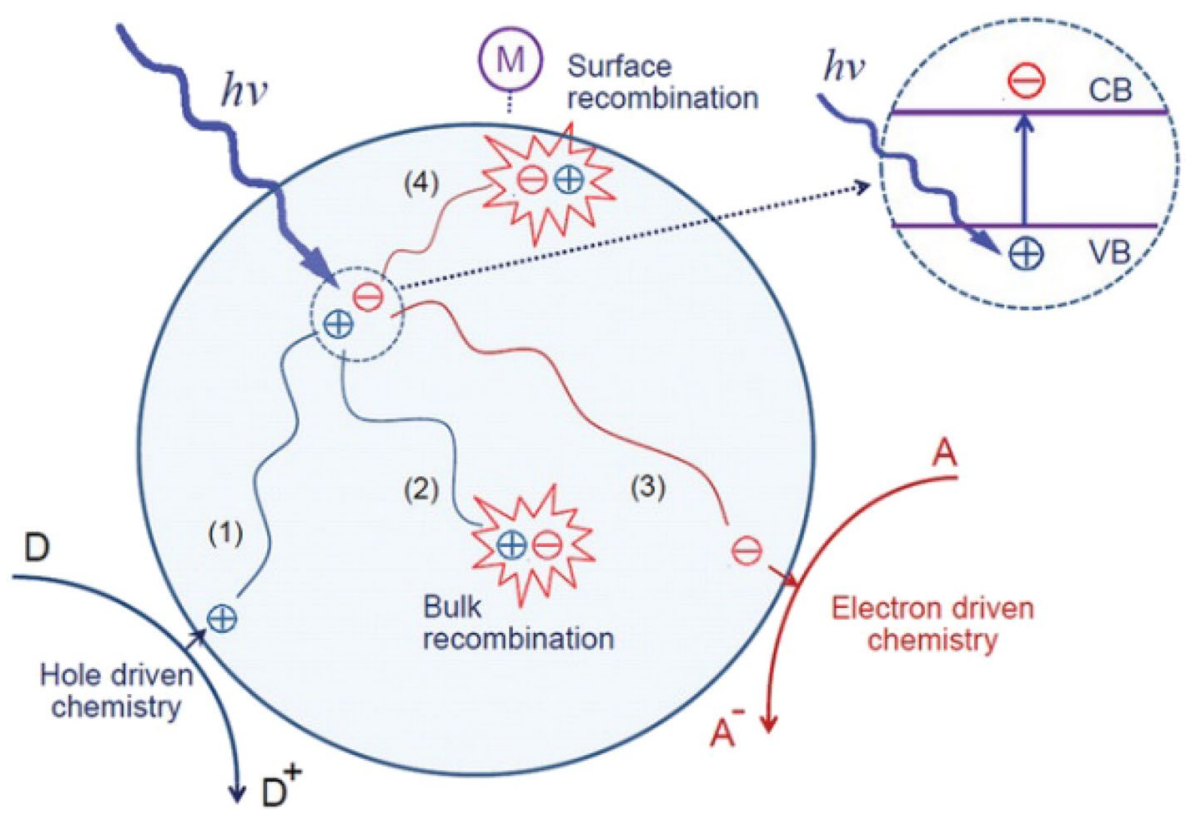


efficiency of RhB dye reached $90.3 \%$ after $120 \mathrm{~min}$. Zhang et al. [86] compared the photocatalytic degradation efficiency of phenol by several manganese oxides (acidic birnessite (BIR-H), alkaline birnessite (BIR-OH), cryptomelane (CRY) and todorokite (TOD)). After $12 \mathrm{~h}$ of UV-Vis irradiation, the total organic carbon (TOC) removal rate of CRY, BIR-H, TOD and BIR-OH reached $62.1 \%, 43.1 \%, 25.4 \%$ and $22.5 \%$, respectively. Compared to the reactions in the dark condition, UV-Vis exposure improved the TOC removal rates by $55.8 \%, 31.9 \%, 23.4 \%$ and $17.9 \%$.

In summary, the photocatalytic degradation of VOCs on different manganese-based catalysts is listed in Table 2.

\section{Photo-Thermocatalytic Degradation of VOCs on Manganese-Based Catalysts}

Although compared with thermal degradation technology, the thermocatalytic degradation of VOCs has achieved a great reduction in energy consumption, it is still a high energy consumption process. As for the traditional photocatalytic degradation of VOCs, the utilization efficiency of solar energy is very low. Though some studies have extended the photoresponse of various photocatalysts from ultraviolet to visible light or even infrared region by decorating modification, the efficiency is still low [84, 87-90]. Photo-thermocatalytic oxidation, which combines the excellent catalytic efficiency and excellent durability of thermocatalytic oxidation with low energy consumption of photocatalytic oxidation, has become a very effective method for reducing air pollutants. Based on different reaction ways, photo-thermocatalysis can be divided into three categories: photo-assisted thermocatalysis, thermo-assisted photocatalysis and photo-thermal synergetic catalysis. There are very few reports on the use of manganese-based catalysts in thermo-assisted photocatalysis. In this part, we will focus on the use of manganese-based catalysts in photo-assisted thermocatalytic and photo-thermal synergetic catalytic degradation.

\section{Photo-Assisted Thermocatalytic Degradation}

Fundamentally, photo-assisted thermocatalysis is also a kind of thermocatalysis, but the energy primarily comes from light. The catalyst absorbs solar energy and converts solar energy into thermal energy, which increases the temperature of catalyst to the ignition temperature of VOCs and then drives the thermocatalytic reaction [91, 92]. Therefore, to achieve high efficiency in photo-assisted thermocatalytic VOCs degradation, catalysts should not only possess good thermocatalytic performance, but also have excellent photo-thermal conversion efficiency. Yang et al. [91] prepared a hollow sphere ramsdellite $\mathrm{MnO}_{2}\left(\mathrm{R}-\mathrm{MnO}_{2}-\mathrm{HS}\right)$, which exhibits efficient catalytic activity for the purification of benzene under the whole solar spectrum. Excellent photo-assisted thermocatalysis efficiency was also observed under visible-infrared and infrared radiation. The excellent catalytic activity of $\mathrm{R}-\mathrm{MnO}_{2}-\mathrm{HS}$ was resulted from its great thermocatalytic activity and efficient photo-thermal conversion efficiency in the whole solar spectrum. The catalytic efficiency of manganese-based catalysts had been improved by ion doping. Hou et al. [92] showed strong absorption in the whole solar spectrum region through the Ce ion substituted cryptomelane-type octahedral molecular sieve (OMS-2) catalyst. The catalyst could effectively convert the absorbed solar energy to thermal energy, which significantly increased the temperature of the catalyst. Combined with the efficient photo-thermal conversion and excellent thermocatalytic activity, the efficient degradation of benzene, toluene, acetone and other VOCs was realized under the irradiation of whole solar spectrum, visible-infrared and infrared light. Moreover, the catalyst still maintained stable activity after 40 cycles, which indicated the excellent durability of the catalyst (Fig. 7) [92]. Interestingly, the catalyst had no photocatalytic activity through the traditional photocatalytic route at room temperature. $\mathrm{Li}$ et al. [93] synthesized $\mathrm{CeO}_{2} /$ $\mathrm{LaMnO}_{3}$, which realized the efficient photo-thermocatalytic degradation of VOCs under infrared irradiation. Wang et al. [94] reported the synthesis of $\mathrm{MnO}_{2}$ and graphene nanohybrid $\left(\mathrm{MnO}_{2}-\mathrm{G}\right)$. The as-synthesized nanohybrid showed better $\mathrm{HCHO}$ oxidation efficiency than pure $\mathrm{MnO}_{2}$ or graphene

Table 2 Comparison of photocatalytic degradation of VOCs on different manganese-based catalysts

\begin{tabular}{llll}
\hline Catalyst & Synthesis method & Species & Light source \\
\hline $\mathrm{MnO}_{2} / \mathrm{RGO}$ & Hydrothermal method & Neutral red in water & Visible irradiation \\
$\mathrm{MnO}_{2}$ with Mn vacancies & Hydrothermal method & Formaldehyde & UV-visible irradiation \\
$\mathrm{MnO}_{x} / \mathrm{TiO}_{2}$ & Hydrothermal method & Benzene & Solar spectrum irradiation \\
$\mathrm{Mn}_{2} \mathrm{O}_{3} / \mathrm{Mn}_{3} \mathrm{O}_{4} / \mathrm{MnO}_{2}$ heterojunction & Oxone induced strategy & Ciprofloxacin & Visible irradiation \\
$\mathrm{Mg}-\mathrm{doped} \mathrm{OMS}-2$ nanorod $_{\beta-\mathrm{MnO}_{2} \text { nanotubes }}^{\text {Hydrothermal method }}$ & Benzene & UV-Vis-IR \\
BIR-H, BIR-OH, CRY, TOD & Sol-gel method & RhB dye & Visible irradiation \\
\hline
\end{tabular}



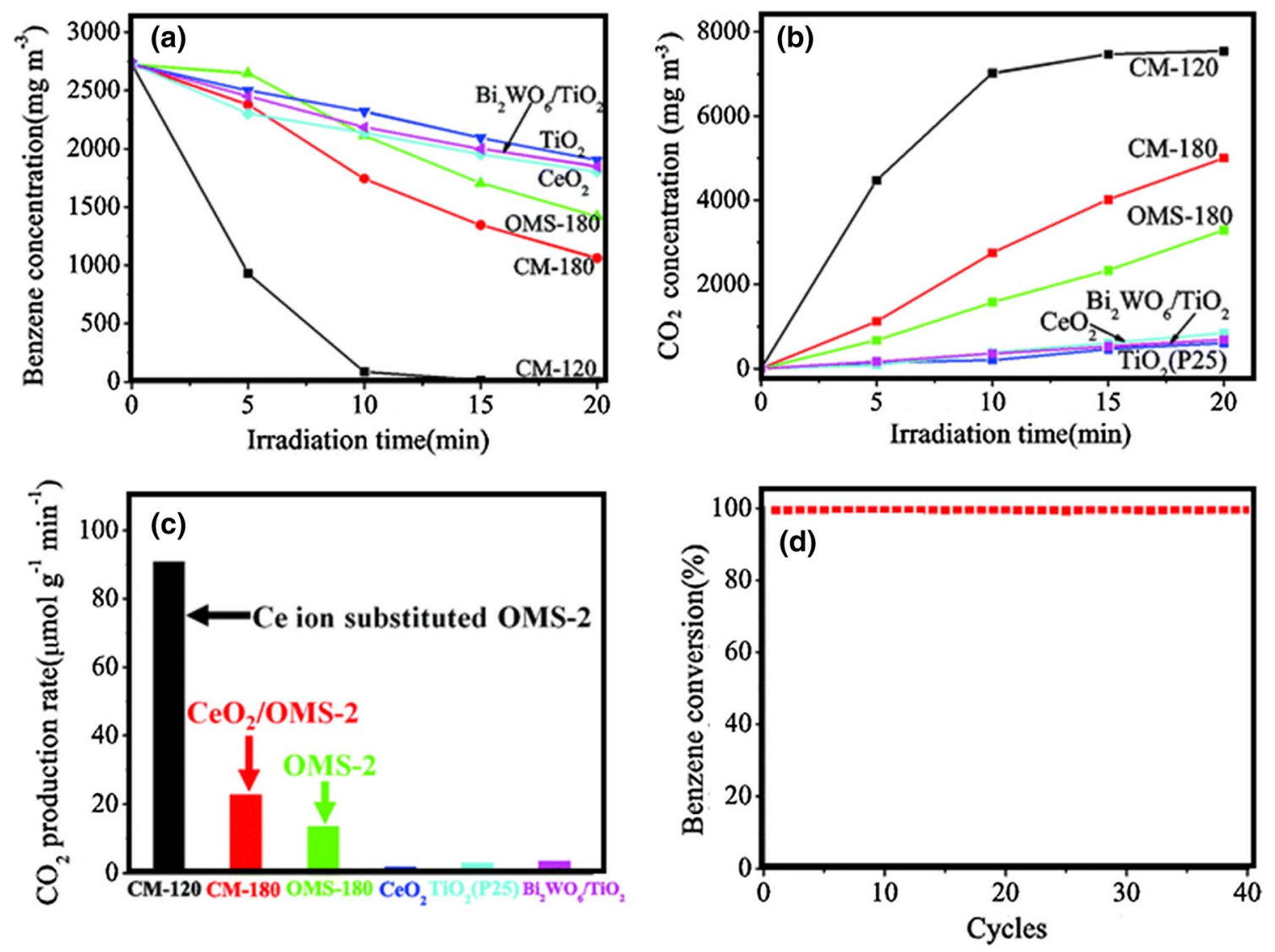

Fig. 7 a Time course of benzene concentration, $\mathbf{b ~} \mathrm{CO}_{2}$ produced from benzene oxidation, $\mathbf{c} \mathrm{CO}_{2}$ produced for benzene oxidation on the catalysts, $\mathbf{d}$ the durability of CM-120 for the benzene oxidation (the

reaction time of every cycle, $20 \mathrm{~min}$ ) under the full solar spectrum irradiation of the Xe lamp. Reprinted with permission from Ref. [92]. Copyright 2015 Royal Society of Chemistry

under the whole solar spectrum. The excellent photo-thermal effect of graphene played an essential role in the catalytic reaction. In addition, the decorations of $\mathrm{Mg}, \mathrm{Fe}, \mathrm{Cu}$ and other non-noble metal ions also significantly improved the photo-thermocatalytic activity of manganese-based catalysts under UV-Vis-IR irradiation [95, 96].

Defect engineering, which involves the manipulation of the types, concentrations and spatial distributions of defects, is considered to be one of the most effective strategies to regulate the electronic structure of materials and improve the catalytic performance [97]. Lee et al. [98] prepared mesoporous copper manganese oxides exhibiting better performances for the catalytic oxidation of benzene, achieving the best benzene conversion rate of $90 \%$ at around $219^{\circ} \mathrm{C}$, which is $23{ }^{\circ} \mathrm{C}$ lower than that for mesoporous manganese oxides. The reason was that the desorption of lattice oxygen caused by copper addition in the manganese oxide, increasing the concentration of oxygen vacancy defects (OVDs) on the catalyst surfaces. Mao et al. [83] also reported the synthesis of OMS-2 nanorod catalysts with different OVDs concentrations. The catalysts showed great activity and excellent durability toward the oxidation of benzene, toluene, acetone

and other VOCs under the irradiation of full solar spectrum, visible-infrared and infrared light.

Noble metals, such as $\mathrm{Au}, \mathrm{Ag}$ and $\mathrm{Pt}$, exhibit unique surface plasmon resonance (SPR) effect, which absorb and scatter light strongly [91]. Therefore, to improve the light harvesting ability of the catalysts, and thus achieve better photo-thermocatalytic performance, metal nanoparticles with strong SPR effect are incorporated into manganesebased catalysts. Ali et al. [59] synthesized Au-Mn/tripleoxide catalyst which showed great catalytic activity in propane oxidation due to the strong synergism between $\mathrm{Mn}$ and Au. $\mathrm{Ag} / \mathrm{MnO}_{x}$ and $\mathrm{Pt} / \mathrm{MnO}_{x}$ also have been synthesized as efficient catalysts toward VOCs degradation under natural conditions $[99,100]$.

\section{Photo-Thermal Synergetic Catalytic Degradation}

Photo-thermal synergetic catalysis integrates the advantages of both photocatalysis $\left(\mathrm{TiO}_{2}\right)$ and thermocatalysis (manganese-based catalysts) and shows better performance through synergistic effect. Ma et al. [44] prepared $\mathrm{MnO}_{x} / \mathrm{TiO}_{2}$ nanocomposites and found that there was a synergistic effect 
between $\mathrm{TiO}_{2}$ photocatalysis and $\mathrm{MnO}_{2}$ thermocatalysis. This synergistic effect significantly improved the catalytic activity of $\mathrm{MnO}_{x} / \mathrm{TiO}_{2}$ nanocomposites. Excellent catalytic activity and durability of $\mathrm{MnO}_{\mathrm{x}} / \mathrm{TiO}_{2}$ for the gas-phase oxidation of benzene under full solar and visible-infrared light irradiation were demonstrated. Ren et al. [61] prepared Ce$\mathrm{MnO}_{x}$ catalyst by coprecipitation method and then deposited $\mathrm{TiO}_{2}$ and $\mathrm{Pt}$, respectively, to obtain $\mathrm{Pt}-\mathrm{TiO}_{2} / \mathrm{Ce}-\mathrm{MnO}_{x}$ catalyst. The kinetic constant of the photo-thermocatalytic degradation of benzene $\left(k_{\mathrm{TP}}=5.17 \mathrm{mg}^{1 / 2}\left(\mathrm{~m}^{3 / 2} \mathrm{~h}\right)\right)$ was 7.72 times that of single photocatalysis $\left(k_{\mathrm{P}}=0.67 \mathrm{mg}^{1 / 2}\left(\mathrm{~m}^{3 / 2} \mathrm{~h}\right)\right)$ and 2.32 times the sum of the kinetic constants of the photocatalysis and thermocatalysis $\left(k_{\mathrm{T}}=1.55 \mathrm{mg}^{1 / 2}\left(\mathrm{~m}^{3 / 2} \mathrm{~h}\right)\right)$. This result indicated that the photocatalytic and thermocatalytic of benzene on $\mathrm{Pt}-\mathrm{TiO}_{2} / \mathrm{Ce}-\mathrm{MnO}_{x}$ catalyst had remarkable synergistic effect (Fig. 8a) [61]. Lan et al. [101] prepared $\mathrm{MnO}_{x} / \mathrm{TiO}_{2}$ nanocomposites with dominant facets (Fig. 8b). The catalytic realized the synergistic effect of photo-assisted thermocatalysis and photocatalysis, which effectively extended the catalytic benzene oxidation response from ultraviolet to the whole solar spectral region.

In summary, the photo-thermocatalytic degradation of VOCs on different manganese-based catalysts is listed in Table 3.

\section{Prospects}

Although significant progress has been made in the efficient catalytic degradation of VOCs with manganesebased catalysts, there are still some challenges and possible opportunities. Firstly, manganese oxide is a narrow band gap semiconductor, which has good photo-thermal conversion performance. There are only a few reports on the use of manganese-based catalysts for photocatalytic and photothermocatalytic reactions. More efforts should be devoted into this research field. Moreover, noble metals are often doped into manganese-based catalysts to improve their

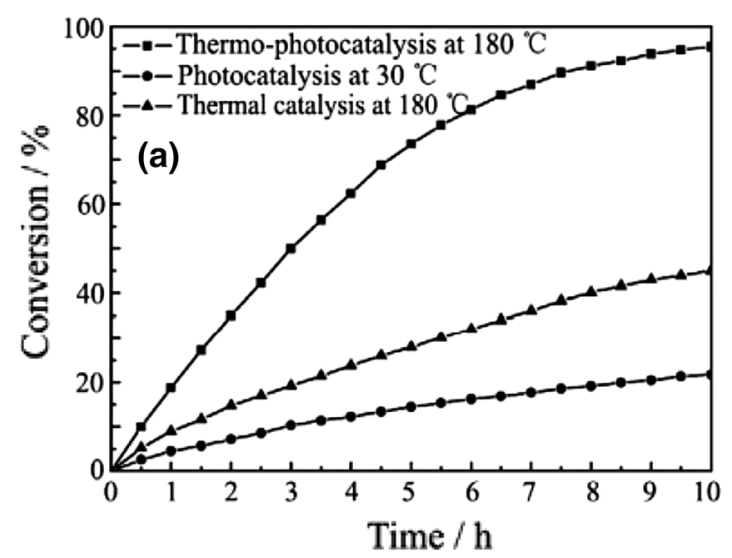

Fig. 8 a A comparison of photocatalysis, thermocatalysis and photothermocatalysis for the catalyst $\mathrm{Pt}-\mathrm{TiO}_{2} / \mathrm{Ce}-\mathrm{MnO}_{x} \quad \mathrm{Ti}_{40 \%}-\mathrm{Pt}_{1.0 \%}$. Reprinted with permission from Ref. [61]. Copyright 2012 Elsevier. b $\mathrm{CO}_{2}$ production rate for benzene oxidation of the $\mathrm{MnO}_{x} / \mathrm{TNS}-\mathrm{C}$ sam-

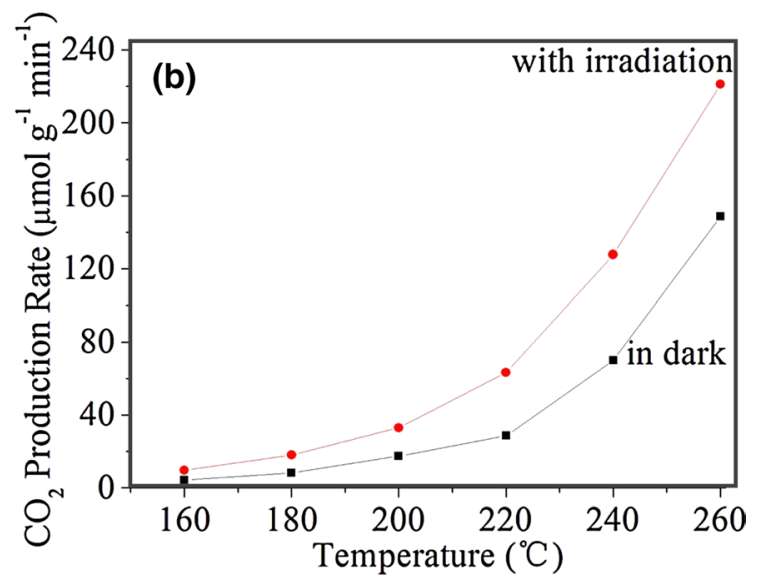

ple in dark and with the irradiation of the Xe lamp at the different temperature. Reprinted with permission from Ref. [101]. Copyright 2016 Elsevier

Table 3 Comparison of photo-thermocatalytic degradation of VOCs on different manganese-based catalysts

\begin{tabular}{|c|c|c|c|c|}
\hline Catalyst & Synthesis method & Species & Result & Refs \\
\hline $\mathrm{R}-\mathrm{MnO}_{2}-\mathrm{HS}$ & Hydrothermal method & Benzene & $\begin{array}{l}\text { Full solar spectrum or Vis-IR irradiation, even under } \\
\text { the infrared irradiation }\end{array}$ & {$[91]$} \\
\hline $\mathrm{CeO}_{2} / \mathrm{LaMnO}_{3}$ & Citric acid combustion method & Toluene & $89 \%$ conversion under IR irradiation & [93] \\
\hline $\mathrm{MnO}_{2}-\mathrm{G}$ & Hydrothermal method & Formaldehyde & Near infrared radiation & [94] \\
\hline Fe-doped OMS-2 & Hydrothermal method & Benzene & UV-Vis-IR & {$[95]$} \\
\hline $\begin{array}{l}\mathrm{Cu} \text {-doped ramsdellite } \\
\mathrm{MnO}_{2} \text { nanosheet }\end{array}$ & Hydrothermal method & $\mathrm{CO}$ & UV-Vis-IR & {$[96]$} \\
\hline $\mathrm{Ag} / \mathrm{MnO}_{x}$ & Hydrothermal method & Formaldehyde & Nature solar light & [99] \\
\hline $\mathrm{Pt} / \mathrm{MnO}_{x}-\mathrm{CeO}_{2}$ & Coprecipitation method & Formaldehyde & $100 \%$ conversion at ambient temperature & [100] \\
\hline $\mathrm{MnO}_{x} / \mathrm{TiO}_{2}$ & Hydrothermal method & Benzene & Full solar spectrum light and visible-infrared light & [44] \\
\hline
\end{tabular}


catalytic performance. However, the high cost of noble metals strongly restricts their wide application. Therefore, it is necessary to develop catalysts doped with less amount of noble metals or earth-abundant elements. In addition, although a lot of researches on the catalytic degradation of VOC by manganese-based catalysts have been carried out, there is still a lack of effective understanding of the specific reaction pathway. Therefore, more experiments and theoretical simulations are needed to deeply understand the pathway of decomposition of VOCs by manganese-based catalysts, such as the combination of in situ characterization and computational chemistry.

\section{Conclusions}

This paper summarizes the state-of-the-art application of manganese-based catalysts in VOCs catalytic degradation. The optimization of manganese-based catalysts by means of structural design, decorating modification and defect engineering is introduced. Proper structure design can improve the specific surface area, increase the active sites and improve the catalytic performance. Certain amount of decorating with other metal ions, especially noble metals, can greatly improve the catalytic performance. Defect engineering is considered to be one of the most effective strategies to regulate the electronic structure of materials, which greatly improve the catalytic performance of the catalyst.

Acknowledgements This work was financially supported by the National Natural Science Foundation of China (No. 22071173) and the Natural Science Foundation of Tianjin City (No. 20JCJQJC00050).

\section{Declarations}

Conflict of interest The authors declare that there are no conflicts of interest.

Open Access This article is licensed under a Creative Commons Attribution 4.0 International License, which permits use, sharing, adaptation, distribution and reproduction in any medium or format, as long as you give appropriate credit to the original author(s) and the source, provide a link to the Creative Commons licence, and indicate if changes were made. The images or other third party material in this article are included in the article's Creative Commons licence, unless indicated otherwise in a credit line to the material. If material is not included in the article's Creative Commons licence and your intended use is not permitted by statutory regulation or exceeds the permitted use, you will need to obtain permission directly from the copyright holder. To view a copy of this licence, visit http://creativecommons.org/licenses/by/4.0/.

\section{References}

1. Plocoste T, Dorville JF, Monjoly S et al (2018) Assessment of nitrogen oxides and ground-level ozone behavior in a dense air quality station network: case study in the Lesser Antilles Arc. J Air Waste Manag Assoc 68(12):1278-1300

2. Obanya HE, Amaeze NH, Togunde O et al (2018) Air pollution monitoring around residential and transportation sector locations in Lagos mainland. J Heal Pollut 8(19):180903. https://doi.org/ 10.5696/2156-9614-8.19.180903

3. He C, Cheng J, Zhang X et al (2019) Recent advances in the catalytic oxidation of volatile organic compounds: a review based on pollutant sorts and sources. Chem Rev 119(7):4471-4568

4. Lu H, Lyu X, Cheng H et al (2019) Overview on the spatialtemporal characteristics of the ozone formation regime in China. Environ Sci Process Impacts 21(6):916-929

5. Li J, Wang Z, Chen L et al (2020) WRF-Chem simulations of ozone pollution and control strategy in petrochemical industrialized and heavily polluted Lanzhou City, Northwestern China. Sci Total Environ 737:139835

6. Park JH, Goldstein AH, Timkovsky J et al (2013) Active atmosphere-ecosystem exchange of the vast majority of detected volatile organic compounds. Science 341(6146):643-647

7. Jiang N, Li XC, Kong XQ et al (2021) The post plasma-catalytic decomposition of toluene over K-modified OMS-2 catalysts at ambient temperature: effect of $\mathrm{K}^{+}$loading amount and reaction mechanism. J Colloid Interface Sci 598:519-529

8. Chen CY, Zhu J, Chen F et al (2013) Enhanced performance in catalytic combustion of toluene over mesoporous Beta zeolite-supported platinum catalyst. Appl Catal B: Environ 140-141:199-205

9. Huang HB, Xu Y, Feng QY et al (2015) Low temperature catalytic oxidation of volatile organic compounds: a review. Catal Sci Technol 5(5):2649-2669

10. Fang SM, Li YZ, Yang Y et al (2017) Mg-doped OMS-2 nanorods: a highly efficient catalyst for purification of volatile organic compounds with full solar spectrum irradiation. Environ Sci: Nano 4(9):1798-1807

11. Kamal MS, Razzak SA, Hossain MM (2016) Catalytic oxidation of volatile organic compounds (VOCs): a review. Atmos Environ 140:117-134

12. Hu Z, Qiu S, You Y et al (2018) Hydrothermal synthesis of $\mathrm{NiCeO}_{\mathrm{x}}$ nanosheets and its application to the total oxidation of propane. Appl Catal B: Environ 225:110-120

13. Montini T, Melchionna M, Monai M et al (2016) Fundamentals and catalytic applications of $\mathrm{CeO}_{2}$-based materials. Chem Rev 116(10):5987-6041

14. Suárez-Vázquez SI, Gil S, García-Vargas JM et al (2018) Catalytic oxidation of toluene by $\operatorname{SrTi}_{1-X} \mathrm{~B}_{X} \mathrm{O}_{3}(\mathrm{~B}=\mathrm{Cu}$ and $\mathrm{Mn})$ with dendritic morphology synthesized by one pot hydrothermal route. Appl Catal B: Environ 223:201-208

15. Veerapandian SKP, Ye ZP, Giraudon JM et al (2019) Plasma assisted $\mathrm{Cu}-\mathrm{Mn}$ mixed oxide catalysts for trichloroethylene abatement in moist air. J Hazard Mater 379:120781

16. Guo H, Lee SC, Chan LY et al (2004) Risk assessment of exposure to volatile organic compounds in different indoor environments. Environ Res 94(1):57-66

17. Xu TZ, Zheng H, Zhang PY (2018) Performance of an innovative VUV-PCO purifier with nanoporous $\mathrm{TiO}_{2}$ film for simultaneous elimination of VOCs and by-product ozone in indoor air. Build Environ 142:379-387

18. Jia S, Sankaran G, Wang B et al (2019) Exposure and risk assessment of volatile organic compounds and airborne phthalates in Singapore's Child Care Centers. Chemosphere 224:85-92

19. Quirós-Alcalá L, Wilson S, Witherspoon N et al (2016) Volatile organic compounds and particulate matter in child care facilities in the district of Columbia: results from a pilot study. Environ Res 146:116-124

20. Gao M, Liu W, Wang H et al (2021) Emission factors and characteristics of volatile organic compounds (VOCs) from adhesive 
application in indoor decoration in China. Sci Total Environ 779:145169

21. Huang Y, Ho SS, Lu Y et al (2016) Removal of indoor volatile organic compounds via photocatalytic oxidation: a short review and prospect. Molecules 21(1):56

22. Zavala M, Brune WH, Velasco E et al (2020) Changes in ozone production and VOC reactivity in the atmosphere of the Mexico City Metropolitan Area. Atmos Environ 238:117747

23. Li SD, Wang DD, Wu XF et al (2020) Recent advance on VOCs oxidation over layered double hydroxides derived mixed metal oxides. Chin J Catal 41(4):550-560

24. Tan X, Huang XS, Zou YL et al (2018) Synthesis and characterization of Co-doped brookite titania photocatalysts with high photocatalytic activity. Trans Tianjin Univ 24(2):111-122

25. Zang M, Zhao CC, Wang YQ et al (2019) A review of recent advances in catalytic combustion of VOCs on perovskite-type catalysts. J Saudi Chem Soc 23(6):645-654

26. Vikrant K, Park CM, Kim KH et al (2019) Recent advancements in photocatalyst-based platforms for the destruction of gaseous benzene: performance evaluation of different modes of photocatalytic operations and against adsorption techniques. J Photochem Photobiol C: Photochem Rev 41:100316

27. Ahmad J, Wahid M, Majid K (2020) In situ construction of hybrid $\mathrm{MnO}_{2} @ \mathrm{GO}$ heterostructures for enhanced visible light photocatalytic, anti-inflammatory and anti-oxidant activity. New J Chem 44(26):11092-11104

28. Schiavon M, Scapinello M, Tosi P et al (2015) Potential of non-thermal plasmas for helping the biodegradation of volatile organic compounds (VOCs) released by waste management plants. J Clean Prod 104:211-219

29. Fang L, Liu WW, Chen DN et al (2019) Source profiles of volatile organic compounds (VOCs) from typical solvent-based industries in Beijing. Huan Jing Ke Xue 40(10):4395-4403

30. Liu RR, Chen JY, Li GY et al (2017) Using an integrated decontamination technique to remove VOCs and attenuate health risks from an e-waste dismantling workshop. Chem Eng J 318:57-63

31. Chen JY, Liu RR, Gao YP et al (2017) Preferential purification of oxygenated volatile organic compounds than monoaromatics emitted from paint spray booth and risk attenuation by the integrated decontamination technique. J Clean Prod 148:268-275

32. Xu L, Li YH, Zhu J et al (2019) Removal of toluene by adsorption/desorption using ultra-stable Y zeolite. Trans Tianjin Univ 25(4):312-321

33. Cabanes A, Fullana A (2021) New methods to remove volatile organic compounds from post-consumer plastic waste. Sci Total Environ 758:144066

34. Zhang ZL, Chen JY, Gao YP et al (2018) A coupled technique to eliminate overall nonpolar and polar volatile organic compounds from paint production industry. J Clean Prod 185:266-274

35. Yang CT, Miao G, Pi YH et al (2019) Abatement of various types of VOCs by adsorption/catalytic oxidation: a review. Chem Eng J 370:1128-1153

36. Piumetti M, Fino D, Russo N (2015) Mesoporous manganese oxides prepared by solution combustion synthesis as catalysts for the total oxidation of VOCs. Appl Catal B: Environ 163:277-287

37. Zhang ZX, Jiang Z, Shangguan WF (2016) Low-temperature catalysis for VOCs removal in technology and application: a state-of-the-art review. Catal Today 264:270-278

38. Yang WH, Su ZA, Xu ZH et al (2020) Comparative study of $\alpha-$, $\beta-, \gamma-$ and $\delta-\mathrm{MnO}_{2}$ on toluene oxidation: oxygen vacancies and reaction intermediates. Appl Catal B: Environ 260:118150

39. Abdi Z, Bagheri R, Reza Mohammadi M et al (2021) In situ synthesis of manganese oxide as an oxygen-evolving catalyst: A new strategy. Chem Eur J 27(4):1330-1336

40. Liu L, Li J, Zhang H et al (2019) In situ fabrication of highly active $\gamma-\mathrm{MnO}_{2} / \mathrm{SmMnO}_{3}$ catalyst for deep catalytic oxidation of gaseous benzene, ethylbenzene, toluene, and o-xylene. J Hazard Mater 362:178-186

41. Liao YN, Zhang X, Peng RS et al (2017) Catalytic properties of manganese oxide polyhedra with hollow and solid morphologies in toluene removal. Appl Surf Sci 405:20-28

42. Liu P, Wei GL, He HP et al (2019) The catalytic oxidation of formaldehyde over palygorskite-supported copper and manganese oxides: catalytic deactivation and regeneration. Appl Surf Sci 464:287-293

43. Shu YJ, Xu Y, Huang HB et al (2018) Catalytic oxidation of VOCs over $\mathrm{Mn} / \mathrm{TiO}_{2} /$ activated carbon under $185 \mathrm{~nm}$ VUV irradiation. Chemosphere 208:550-558

44. Ma Y, Li YZ, Mao MY et al (2015) Synergetic effect between photocatalysis on $\mathrm{TiO}_{2}$ and solar light-driven thermocatalysis on $\mathrm{MnO}_{x}$ for benzene purification on $\mathrm{MnO}_{x} / \mathrm{TiO}_{2}$ nanocomposites. J Mater Chem A 3(10):5509-5516

45. Tarjomannejad A, Farzi A, Niaei A et al (2016) An experimental and kinetic study of toluene oxidation over LaMn1- ${ }_{\mathrm{x}} \mathrm{B}_{\mathrm{x}} \mathrm{O}_{3}$ and $\mathrm{La}_{0.8} \mathrm{~A}_{0.2} \mathrm{Mn}_{0.3} \mathrm{~B}_{0.7} \mathrm{O}_{3}(\mathrm{~A}=\mathrm{Sr}, \mathrm{Ce}$ and $\mathrm{B}=\mathrm{Cu}, \mathrm{Fe})$ nanoperovskite catalysts. Korean J Chem Eng 33(9):2628-2637

46. Wang T, Wang JY, Sun YM (2019) Origin of electronic structure dependent activity of spinel $\mathrm{ZnNixCo}_{2-\mathrm{x}} \mathrm{O}_{4}$ oxides for complete methane oxidation. Appl Catal B: Environ 256:117844

47. Utsumi S, Vallejos-Burgos FE, Campos CM et al (2007) Preparation and characterization of inexpensive heterogeneous catalysts for air pollution control: two case studies. Catal Today 123(1-4):208-217

48. Zhang S, Liu SJ, Zhu XC et al (2019) Low temperature catalytic oxidation of propane over cobalt-cerium spinel oxides catalysts. Appl Surf Sci 479:1132-1140

49. He C, Li P, Cheng J et al (2010) A comprehensive study of deep catalytic oxidation of benzene, toluene, ethyl acetate, and their mixtures over Pd/ZSM-5 catalyst: mutual effects and kinetics. Water Air Soil Pollut 209(1-4):365-376

50. Du Y, Zou J, Guo Y et al (2021) A novel viewpoint on the surface adsorbed oxygen and the atom doping in the catalytic oxidation of toluene over low-Pt bimetal catalysts. Appl Catal A: Gen. 609:117913

51. Hu MC, Yao ZH, Hui KN et al (2017) Novel mechanistic view of catalytic ozonation of gaseous toluene by dual-site kinetic modelling. Chem Eng J 308:710-718

52. Al-Sakkari EG, El-Sheltawy ST, Attia NK et al (2017) Kinetic study of soybean oil methanolysis using cement kiln dust as a heterogeneous catalyst for biodiesel production. Appl Catal B: Environ 206:146-157

53. Maghsoodi S, Towfighi J, Khodadadi A et al (2013) The effects of excess manganese in nano-size lanthanum manganite perovskite on enhancement of trichloroethylene oxidation activity. Chem Eng J 215-216:827-837

54. Wang X, Zhao W, Wu X et al (2017) Kinetic study of soybean oil methanolysis using cement kiln dust as a heterogeneous catalyst for biodiesel production. Appl Surf Sci 426:1198-1205

55. Pan H, Jian YF, Chen CW et al (2017) Sphere-shaped $\mathrm{Mn}_{3} \mathrm{O}_{4}$ catalyst with remarkable low-temperature activity for methyl-ethyl-ketone combustion. Environ Sci Technol 51(11):6288-6297

56. Tomatis M, Xu HH, He J et al (2016) Recent development of catalysts for removal of volatile organic compounds in flue gas by combustion: a review. J Chem 2016:1-15

57. Carabineiro SAC, Chen X, Martynyuk O et al (2015) Gold supported on metal oxides for volatile organic compounds total oxidation. Catal Today 244:103-114

58. Gao H, Dong Y, Zhou S (2019) Catalytic combustion of volatile organic compounds by noble metals catalysts. Environ Eng $37: 136-141$ 
59. Ali AM, Daous MA, Khamis AAM et al (2015) Strong synergism between gold and manganese in an Au-Mn/triple-oxide-support (TOS) oxidation catalyst. Appl Catal A: Gen 489:24-31

60. Xu H, Yan N, Qu Z et al (2017) Gaseous heterogeneous catalytic reactions over Mn-based oxides for environmental applications: A critical review. Environ Sci Technol 51(16):8879-8892

61. Ren CJ, Zhou LN, Duan YW et al (2012) Synergetic effect of thermo-photocatalytic oxidation of benzene on $\mathrm{Pt}-\mathrm{TiO}_{2} / \mathrm{Ce}-$ $\mathrm{MnO}_{x}$. J Rare Earths 30(11):1106-1111

62. Rong SP, Zhang PY, Liu F et al (2018) Engineering crystal facet of $\alpha-\mathrm{MnO}_{2}$ nanowire for highly efficient catalytic oxidation of carcinogenic airborne formaldehyde. ACS Catal 8(4):3435-3446

63. Dong AQ, Gao S, Wan X et al (2020) Labile oxygen promotion of the catalytic oxidation of acetone over a robust ternary $\mathrm{Mn}$-based mullite $\mathrm{GdMn}_{2} \mathrm{O}_{5}$. Appl Catal B: Environ 271:118932

64. Ling YF, Ma QL, Yu YF et al (2021) Optimization strategies for selective $\mathrm{CO}_{2}$ electroreduction to fuels. Trans Tianjin Univ 27(3):180-200

65. Li K, Chen C, Zhang HB et al (2019) Effects of phase structure of $\mathrm{MnO}_{2}$ and morphology of $\delta-\mathrm{MnO}_{2}$ on toluene catalytic oxidation. Appl Surf Sci 496:143662

66. Li DY, Wu XF, Chen YF (2013) Synthesis of hierarchical hollow $\mathrm{MnO}_{2}$ microspheres and potential application in abatement of VOCs. J Phys Chem C 117(21):11040-11046

67. De Luna MDG, Millanar JM, Yodsa-Nga A et al (2017) Gas phase catalytic oxidation of VOCS using hydrothermally synthesized nest-like K-OMS 2 catalyst. Sains Malays 46(2):275-283

68. Nguyen Dinh MT, Nguyen CC, Truong Vu TL et al (2020) Tailoring porous structure, reducibility and $\mathrm{Mn}^{4+}$ fraction of $\varepsilon-\mathrm{MnO}_{2}$ microcubes for the complete oxidation of toluene. Appl Catal A: Gen 595:117473

69. Zhang HY, Sui SH, Zheng XM et al (2019) One-pot synthesis of atomically dispersed $\mathrm{Pt}$ on $\mathrm{MnO}_{2}$ for efficient catalytic decomposition of toluene at low temperatures. Appl Catal B: Environ 257:117878

70. Li J, Shi YJ, Fu XH et al (2021) Effects of Ni substitution on active oxygen species and electronic interactions over $\mathrm{La}_{0.8} \mathrm{Ce}_{0.2} \mathrm{MnO}_{3} /$ mesoporous ZSM-5 for oxidizing $\mathrm{C}_{6} \mathrm{H}_{14}$. Mol Catal 99:111309

71. Fujishima A, Honda K (1972) Electrochemical photolysis of water at a semiconductor electrode. Nature 238(5358):37-38

72. Pruden A, Ollis DF (1983) Photoassisted heterogeneous catalysis: the degradation of trichloroethylene in water. J Catal 82(2):404-417

73. Wang YF, Wang HM, Tan X (2018) Study of 2-propanol photocatalytic degradation on surface of phase-ratio-controlled $\mathrm{TiO}_{2}$ nanoparticles. Trans Tianjin Univ 24(1):1-7

74. Frank SN, Bard AJ (1977) Heterogeneous photocatalytic oxidation of cyanide ion in aqueous solutions at titanium dioxide powder. J Am Chem Soc 99(1):303-304

75. Frank SN, Bard AJ (1977) Heterogeneous photocatalytic oxidation of cyanide and sulfite in aqueous solutions at semiconductor powders. J Phys Chem 81(15):1484-1488

76. Kraeutler B, Bard AJ (1978) Heterogeneous photocatalytic preparation of supported catalysts photodeposition of platinum on titanium dioxide powder and other substrates. J Am Chem Soc 100(13):4317-4318

77. Zhuang Y, Sun LM, Zeng SY et al (2019) Engineering migration pathway for effective separation of photogenerated carriers on multicomponent heterojunctions coated with nitrogen-doped carbon. Chem - A Eur J 25(62):14133-14139

78. Zhang LS, Lian JS, Wu LY et al (2014) Synthesis of a thin-layer $\mathrm{MnO}_{2}$ nanosheet-coated $\mathrm{Fe}_{3} \mathrm{O}_{4}$ nanocomposite as a magnetically separable photocatalyst. Langmuir 30(23):7006-7013

79. Rahmat M, Rehman A, Rahmat S et al (2019) Highly efficient removal of crystal violet dye from water by $\mathrm{MnO}_{2}$ based nanofibrous mesh/photocatalytic process. J Mater Res Technol 8(6):5149-5159

80. Chhabra T, Kumar A, Bahuguna A et al (2019) Reduced graphene oxide supported $\mathrm{MnO}_{2}$ nanorods as recyclable and efficient adsorptive photocatalysts for pollutants removal. Vacuum 160:333-346

81. Guo Q, Zhou CY, Ma ZB et al (2019) Fundamentals of TiO 2 photocatalysis: concepts, mechanisms, and challenges. Adv Mater 31(50): 1901997

82. Zhang HY, Rong SP, Zhang PY (2021) Photoinduced simultaneous thermal and photocatalytic activities of $\mathrm{MnO}_{2}$ revealed by femtosecond transient absorption spectroscopy. ACS Appl Mater Interfaces 13(16): 18944-18953

83. Mao MY, Li YZ, Hou JT et al (2015) Extremely efficient full solar spectrum light driven thermocatalytic activity for the oxidation of VOCs on OMS-2 nanorod catalyst. Appl Catal B: Environ 174-175:496-503

84. Zhao JH, Zhao ZW, Li N et al (2018) Visible-light-driven photocatalytic degradation of ciprofloxacin by a ternary $\mathrm{Mn}_{2} \mathrm{O}_{3} /$ $\mathrm{Mn}_{3} \mathrm{O}_{4} / \mathrm{MnO}_{2}$ valence state heterojunction. Chem Eng $\mathrm{J}$ 353:805-813

85. Chan YL, Pung SY, Sreekantan S et al (2016) Photocatalytic activity of $\beta-\mathrm{MnO}_{2}$ nanotubes grown on PET fibre under visible light irradiation. J Exp Nanosci 11(8):603-618

86. Zhang Q, Cheng X, Zheng C et al (2011) Roles of manganese oxides in degradation of phenol under UV-Vis irradiation: adsorption, oxidation, and photocatalysis. J Environ Sci (China) 23(11):1904-1910

87. Guo RN, Wang YY, Li JJ et al (2020) Sulfamethoxazole degradation by visible light assisted peroxymonosulfate process based on nanohybrid manganese dioxide incorporating ferric oxide. Appl Catal B: Environ 278:119297

88. Shang QQ, Tan X, Yu T et al (2015) Efficient gaseous toluene photoconversion on graphene-titanium dioxide nanocomposites with dominate exposed 001 facets. J Colloid Interface Sci 455:134-144

89. Wang YF, Zhang ZY, Shang QQ et al (2018) Synthesis and optimization of $\mathrm{TiO} 2 /$ graphene with exposed 001 facets based on response surface methodology and evaluation of enhanced photocatalytic activity. Trans Tianjin Univ 24(5):415-423

90. Pany S, Naik B, Martha S et al (2014) Plasmon induced nano Au particle decorated over $\mathrm{S}, \mathrm{N}$-modified $\mathrm{TiO} 2$ for exceptional photocatalytic hydrogen evolution under visible light. ACS Appl Mater Interfaces 6(2):839-846

91. Yang Y, Li YZ, Mao MY et al (2017) UV-visible-infrared light driven thermocatalysis for environmental purification on ramsdellite $\mathrm{MnO}_{2}$ hollow spheres considerably promoted by a novel photoactivation. ACS Appl Mater Interfaces 9(3):2350-2357

92. Hou J, Li Y, Mao M et al (2015) Full solar spectrum light driven thermocatalysis with extremely high efficiency on nanostructured Ce ion substituted OMS-2 catalyst for VOCs purification. Nanoscale 7(6):2633-2640

93. Li JJ, Yu EQ, Cai SC et al (2019) Noble metal free, $\mathrm{CeO}_{2} /$ $\mathrm{LaMnO}_{3}$ hybrid achieving efficient photo-thermal catalytic decomposition of volatile organic compounds under IR light. Appl Catal B: Environ 240:141-152

94. Wang JL, Zhang GK, Zhang PY (2018) Graphene-assisted photothermal effect on promoting catalytic activity of layered $\mathrm{MnO}_{2}$ for gaseous formaldehyde oxidation. Appl Catal B: Environ 239:77-85

95. Chen J, Li YZ, Fang SM et al (2018) UV-Vis-infrared lightdriven thermocatalytic abatement of benzene on Fe doped OMS-2 nanorods enhanced by a novel photoactivation. Chem Eng J 332:205-215

96. Yang Y, Li YZ, Zeng M et al (2018) UV-vis-infrared light-driven photothermocatalytic abatement of $\mathrm{CO}$ on $\mathrm{Cu}$ doped ramsdellite 
$\mathrm{MnO}_{2}$ nanosheets enhanced by a photoactivation effect. Appl Catal B: Environ 224:751-760

97. Wang H, Zhang JJ, Hang XD et al (2015) Half-metallicity in single-layered manganese dioxide nanosheets by defect engineering. Angewandte Chemie Int Ed 54(4):1195-1199

98. Lee HJ, Yang JH, You JH et al (2020) Sea-urchin-like mesoporous copper-manganese oxide catalysts: influence of copper on benzene oxidation. J Ind Eng Chem 89:156-165

99. Xu Z, Chen J, Cai SC et al (2019) Biphasic Ag block assisting electron and energy transfer to facilitate photothermal catalytic oxidation of HCHO over manganese oxide. Mater Today Energy 14:100343

100. Tang XF, Chen JL, Huang XM et al (2008) Pt/ $\mathrm{MnO}_{x}-\mathrm{CeO}_{2}$ catalysts for the complete oxidation of formaldehyde at ambient temperature. Appl Catal B: Environ 81(1-2):115-121

101. Lan L, Li YZ, Zeng M et al (2017) Efficient UV-vis-infrared light-driven catalytic abatement of benzene on amorphous manganese oxide supported on anatase $\mathrm{TiO} 2$ nanosheet with dominant 001 facets promoted by a photothermocatalytic synergetic effect. Appl Catal B: Environ 203:494-504

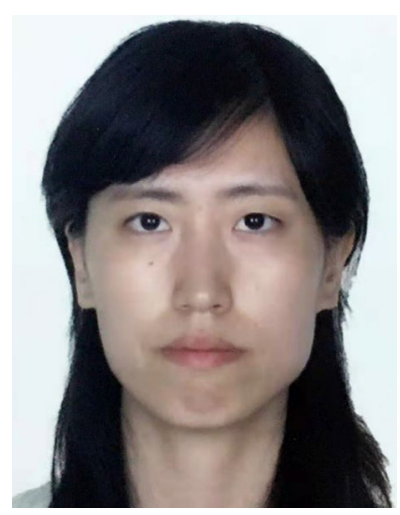

Liping Zhang received her B.E. and M.E. degrees from Southwest Jiaotong University (China) in 2009 and 2012. She completed her Ph.D. study under the supervision of Prof. Fengwei Huo and Prof. Bin Liu at Nanyang Technological University, Singapore in 2018. She then carried out postdoctoral research in Prof. Madhavi Srinivasan's group at Nanyang Technological University, Singapore, in 2018. Currently, she is a Research
Fellow in Prof. Taeghwan Hyeon's group in Seoul National University, Korea. Her research interest focuses on the design and synthesis of nanomaterials for energy-related applications.

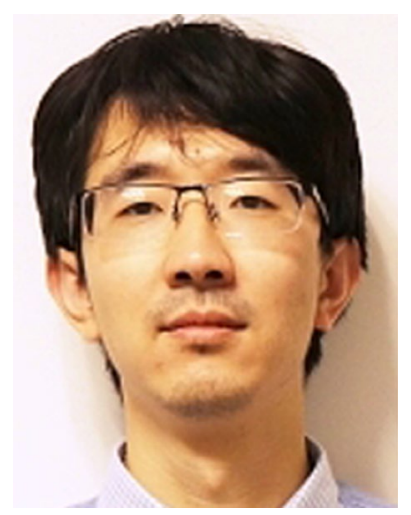

Yifu Yu received his B.E. and M.E. degrees in Chemical Engineering from Tianjin University. He obtained his Ph.D. degree in Chemical Engineering from the same University in 2014. As a Postdoctoral Fellow, he joined Prof. Hua Zhang's group at Nanyang Technological University, Singapore, in 2014. He joined Department of Chemistry at Tianjin University in 2017 as Associate Professor. Currently, he is a full professor at Institute of Molecular Plus in Tianjin University. His research interest

\section{Authors and Affiliations}

\section{Yanbo Li ${ }^{1}$. Shuhe Han ${ }^{1}$ Liping Zhang ${ }^{2}$ - Yifu Yu ${ }^{1}$}

1 Institute of Molecular Plus, Tianjin University, Tianjin 300072, China

2 Center for Nanoparticle Research, Institute for Basic Science (IBS), Seoul, Republic of Korea 